\title{
HINCHADAS \\ CUERPOS SOCIALES, CUERPOS CON AGUANTE
}

HINCHADAS

SOCIAL BODIES, BODIES WITH ENDURANCE

Daniel Zambaglione $e^{1}$

\section{Resumen}

Este texto pertenece a uno de los capítulos de la tesis de maestría "El aguante en el cuerpo: Construcción de identidad de los hinchas de un club de fútbol argentino". Dicho trabajo de investigación se desarrolló sobre un enfoque predominantemente cualitativo, triangulando distintos métodos como la entrevista en profundidad, la observación participante y no participante y grupos focales. En el artículo se presenta a la hinchada, sus componentes constitutivos y sus prácticas particulares de construir masculinidad. Practicas significadas a través de la participación en luchas corporales.

Para los barras el aguante remite a una acción de lucha corporal, es un combate cuerpo a cuerpo contra un igual, donde el "verdadero hombre" debe poseer una postura y acción corporal que lo identifique como buen luchador; el perdedor "corre" por el campo de batalla huyendo del enfrentamiento a golpes de puño.

Palabras clave: masculinidad, cuerpo, corporalidad, aguante, identidad, hinchada.

\section{Abstract}

This text was taken from a chapter of a Master's thesis titled "Bodily endurance, identity construction among the fans of an Argentine football club". This investigative work was developed from a predominantly qualitative focus, triangulating distinct methods such as detailed interviews, participant and non-participant observation and focus groups. In the article, fan groups, their components and specific practices for constructing masculinity are presented; meaningful practices of participation in physical fights.

For the spectators, endurance refers to an action of physical fight; it is a combat, body to body, against an equal, where the 'real man' must possess a bodily posture and action that identifies him as a good fighter. The loser 'runs' through the battlefield, hiding from the confrontation.

Key words: masculinity, body, corporality, endurance, identity, fanbase.

1 Magister. Docente e investigador del Departamento de Educación física de la Facultad de Humanidades y Ciencias de la educación. Universidad Nacional de La Plata. Correos electrónicos: drzamba@ hotmail.com; drzamba@yahoo.com.ar 
El significado simbólico del cuerpo -signo que marca la posición social- no es percibido por los actores (Boltanski, 1975), ya que éste es comúnmente concebido como natural; el cuerpo se construye, es decir, no se nace con un cuerpo. Podemos decir que:

El cuerpo, entonces, como realidad construida, desdibuja sus contornos individuales para aparecer como un cuerpo literalmente social del cual cada cuerpo singular es un ejemplo particularmente construido en la confluencia de significados privados y sociales, familiares, culturales, sencillos y complejos, presentes y pasados, cuya historia comienza antes del nacimiento y se prolonga incluso más allá de la muerte. (Boltansky, 1975 p.1).

Entonces, el cuerpo es en realidad una formación social que exhibe elementos de género, de clase, étnicos, etc. El aguante, -identidad corporal-, articula varias de estas dimensiones, dando como resultado cuerpos aguantadores. En esas prácticas se van constituyendo y subjetivando los cuerpos de los distintos actores que conforman al colectivo social en análisis.

\section{Cuerpos sociales}

Cada grupo social tiene usos y consumos diferenciados y diferenciadores del cuerpo, con lo que produce una concepción corporal específica (Bourdieu, 1994). Así, se construye en el cuerpo parámetros que delimitan prácticas y representaciones como válidas. Esta corporalidad particular se conforma como un eficaz vehículo de definición de pertenencia social, pues identifica y distingue a los iguales y a los otros; acciones y conductas grupales expresan identidades colectivas a través de las cuales se forma un nosotros diferente a un ellos. Los cuerpos socialmente diferenciados permiten la identificación con un nosotros y la distinción respecto de otros cuerpos sociales.

Pero el significado simbólico del cuerpo -signo que marca la posición social- no es percibido por los actores (Boltanski, 1975), ya que el cuerpo es comúnmente concebido como natural. Según Ricardo Crisorio (1998), "el cuerpo se construye (...); es decir, no se nace con un cuerpo. Existe un organismo, qué duda cabe, como existe un sistema nervioso, quién lo dudaría, y huesos, músculos y articulaciones. Pero nada de eso es el cuerpo, el cuerpo no pertenece a lo real" (s.p.) Siguiendo los lineamientos del autor, también podemos decir que "el cuerpo, entonces, como realidad construida, desdibuja sus contornos individuales para aparecer como un cuerpo literalmente social del cual cada cuerpo singular es un ejemplo particularmente construido en la confluencia de significados privados y sociales, familiares, culturales, sencillos y complejos, presentes y pasados, cuya historia comienza antes del nacimiento y se prolonga incluso más allá de la muerte" (s.p.). Entonces, el cuerpo es en realidad una formación social que exhibe elementos de género, de clase, étnicos, etc. El aguante -identidad corporal- articula varias de estas dimensiones, dando como resultado cuerpos aguantadores.

\section{Cuerpos con aguante}

Diez minutos antes de que termine el partido salimos por la puerta de socios. "Vos andate con algunos para la otra entrada", decía uno de los capos, "yo los espero con el resto en la gruta ${ }^{2}$ del lago".. Así se iba armando la estrategia, la logística del combate; era la preparación de la emboscada. As organizaba al resto de sus compañeros de barra, uno de los líderes de la misma observación tomada en el mes mayo de 2008, y así se hizo. Antes de terminar el partido, la $22^{3}$ había salido del estadio. Un grupo estaba esperando en la entrada de socios y otro en la gruta del bosque. Cuando la parcialidad de River comenzó a salir del estadio, aquellos que estaban ubicados cerca de la entrada los empezaron a insultar y a perseguir lanzando piedras. Los simpatizantes de River, sorprendidos, solo atinaron a correr, sin presentar combate, "sin plantarse". El objetivo era llevarlos hacia la gruta, donde entraría en acción el otro grupo. La emboscada estaba funcionando. A metros de la gruta, salió al campo de batalla el numeroso grupo que esperaba oculto. Entonces se desató un feroz enfrentamiento. Golpes de puño, patadas, pedradas, palazos. Cuerpos luchando y gritos conformaban la imagen y el escenario impresionante y espeluznante. Varios hinchas de River fueron retrocediendo en la encarnizada batalla corporal hasta el lago. Los de la 22, con el objeto de pelearse y demostrar su valentía, los seguían. Así, algunos enfrentamientos se dieron en el agua. Rápidamente, llegó la infantería y la caballería. Los miembros de la 22 ahora peleaban cuerpo a cuerpo, con la policía.

Pelear y luchar, son prácticas corporales que trabajan efectivamente en la distinción de aquellos que se la

2 El bosque de la ciudad de La Plata, cercano al lago artificial. 3 La 22 es como se conoce y se la denomina a la barra brava del Club Gimnasia Esgrima La plata, y hace referencia al apodo "el loco". En la jerga de los apostadores de lotería, el numero 22 significa justamente "El loco" . Así se conocía al ya extinto Marcelo Amuchástegui, líder emblemático de la Hinchada en análisis. Pero de él nos ocuparemos mas adelante. 
aguantan. La manera de ser de los hinchas es definida en estos contextos en la lógica del aguante; una lógica que instituye una identidad centrada en el cuerpo. En tanto, en corporalidades aguantadoras, la identificación recorre el camino del aprendizaje y de la exhibición, que no sólo transita la vía del enfrentamiento, ya que sin pelearse, sin "poner el pecho", pueden los hinchas -en determinadas circunstancias- probar su aguante. Con esto queda entendido que el uso del cuerpo aguantador es, en definitiva, el registro último de pertenencia, señal de la identidad.

Dice $H$, un miembro de la hinchada: "Si querés ser de la hinchada, tenés que poner el pecho, sino tomate el palo". Poner el pecho es una muestra del uso característico del cuerpo. En el combate, el aguante se hace cuerpo.

En la situación de lucha entre grupos antagónicos, es el cuerpo de los sujetos el arma de la contienda. Los hinchas, mediante la lucha, ponen el cuerpo para probar su aguante $y$, por ende, ser identificados como hombres. La acción de "poner el cuerpo" en el enfrentamiento puede ser analizada desde los recurrentes discursos de las hinchadas. Los barras hacen referencia al enfrentamiento como una lucha cuerpo a cuerpo, "mano a mano" es la manera en que lo denominan. La lucha "mano a mano" es interpretada por los miembros de la banda como una acción de enfrentamiento en la que el cuerpo se transforma en el elemento que permite valorar las habilidades de los participantesluchadores. Los integrantes de la banda afirman que en un combate se conoce cuál de los contrincantes posee más aguante. Esta afirmación se relaciona con el hecho de que en la situación de enfrentamiento, por medio de la lucha cuerpo a cuerpo, se conocerá quién de los contrincantes "tiene aguante".

El cuerpo en los combates debe tener una postura determinada; si el luchador no va hacia "al frente" o retrocede, se entiende que ha perdido la lucha. El sujeto que "corre", abandonando el campo de batalla, no posee el aguante porque no ha demostrado la posesión de habilidades corporales en la lucha "mano a mano".

Los discursos que refieren a los combates están saturados de términos que denotan acciones corporales, sin incluir las palabras antes analizadas, que refieren al triunfo o al fracaso en la lucha. "Correr" es perder la pelea, el que "corre" por ser perseguido, abandonando el campo de batalla, no ha podido a través de la lucha demostrar su aguante. Los términos antagónicos a la valoración negativa de "correr" son: "pararse", "ir al frente" o "ir para delante". Estas expresiones remiten a acciones contrarias a ser perseguidos. La hinchada que "va al frente", "para delante" o "se para" no es perseguida. En varias oportunidades escuché a los hinchas utilizar como sinónimo aguante y pararse. El aguante genera las nociones nativas de los integrantes de la hinchada: pararse y correr. Éstas surgen como términos contrapuestos que distinguen a los grupos según el conocimiento de las habilidades de lucha y resistencia.

El cuerpo es la herramienta de lucha en los combates. Por esta concepción de extrema valoración de la lucha cuerpo a cuerpo, los hinchas deben conocer las técnicas del aguante corporal, ser hábiles en la lucha y desarrollar tolerancia al dolor, si desean ser considerados como aguantadores. De esta manera, el cuerpo se transforma en el elemento que posibilita manifestar el aguante, a partir de la práctica violenta en el ámbito del fútbol.

Los integrantes de la hinchada emplean su cuerpo como un arma; esta utilización distingue al grupo de otros sectores sociales. La banda usa el cuerpo en las acciones violentas que protagoniza, ostentando los atributos que forman su identidad. ${ }^{4}$

\section{"Los duros"}

En un partido entre Estudiantes y Gimnasia, el clásico de la ciudad de La Plata, jugado en cancha del primero, se produjeron serios incidentes entre la policía y la 22. Desde antes del partido, las provocaciones orales -sumamente ofensivas- hacían prever que algo estaba por suceder, y así fue. La hinchada de Gimnasia estaba intentando entrar a la cancha sin entrada, colándose, de arrebato, como dicen los integrantes del grupo. La policía intentaba frenar la invasión. Gases lacrimógenos y balas de goma intentaban repeler a la 22; éstos, armados con piedras y usando una valla de hierro como ariete, rompieron la resistencia policial y cumplieron su objetivo: ingresar al estadio sin las correspondientes entradas. El triunfo fue festejado por todos los espectadores, quienes, exultantes, cantaban loas de gloria. Cuando todo parecía tranquilizarse, uno de los jefes de la banda, apoyado por algunos subalternos, subieron un carrito de expendio de panchos a lo más

4 La corporalidad aguantadora es muchas veces asociada a los sectores populares. Sin embargo, el colectivo hinchada es un grupo heterogéneo, donde predominan los sectores más bajos de la sociedad pero acompañados por miembros de las clases medias. 
alto de la tribuna y de ahí lo arrojaron a la calle justo sobre un patrullero. Con precisión, dieron en el blanco elegido. Nuevamente, la gresca con la policía se desató. La 22 se trenzó en un durísimo enfrentamiento con la infantería que arremetió con gases lacrimógenos y agua a alta presión.

La policía no "tiene aguante", son "putos". Esta construcción se basa en el empleo de distinto tipo de armas por parte de las fuerzas del orden. A diferencia de los hinchas, la policía no utiliza solamente su cuerpo como herramienta de lucha, ya que están provistos de una innumerable cantidad de elementos utilizados para la lucha. En las situaciones en que se enfrentan la hinchada contra la policía, como sucedió en el episodio antes relatado, los barras utilizaron su cuerpo, sus brazos y piernas para confrontar contra las "fuerzas del orden". En cambio, los policías estaban provistos de palos, gases lacrimógenos y armas de fuego. Además, la policía a través de su uniforme reglamentario y sus accesorios, protege su cuerpo en el enfrentamiento; los cascos, los escudos utilizados por la infantería y los uniformes que resguardan parte de su humanidad, permiten al policía enfrentarse contra el hincha sin temor a ser físicamente golpeado. Ante tanta protección que realiza la policía de su propio cuerpo, los hinchas se encuentran desnudos.

La imagen del enfrentamiento mostraba a un grupo altamente protegido, y a los hinchas con el torso literalmente desnudo, haciendo frente a esta maquinaria represiva. Por esta razón, en un enfrentamiento entre grupos, las fuerzas del orden son catalogadas por los hinchas como "putos". La hinchada "ofrenda el cuerpo" al utilizarlo como herramienta de lucha. En cambio, la policía, protegida por sus uniformes reglamentarios, no arriesga su cuerpo en el enfrentamiento.

Todas estas prácticas de enfrentamiento hacen que uno pertenezca o no a la banda. Para los miembros de la hinchada, el cuerpo se caracteriza por su resistencia, por lo tanto, para ser considerado como miembro deben soportar el uso y abuso de aquellas sustancias que alteran los estados de ánimo. Aquellos hinchas que se emborrachan bebiendo unos pocos tragos, son considerados por sus compañeros, como "flojos" o "blanditos". Éstos, se distinguen de aquellos sujetos cuya capacidad para beber grandes cantidades de bebidas alcohólicas les permite ser considerados como "duros". La desmesurada utilización de drogas y bebidas alcohólicas produce un efecto en los hinchas. El no-hombre no tiene el cuerpo preparado para resistir; por lo tanto los hinchas se burlan de los compañeros que pierden la consciencia rápidamente. Un integrante de la banda nos contaba cómo era un día de partido: "paramos en el boliche de bigote, chupamos unos vinos y arrancamos relocos, descontrolados". Descontrolados, es la marca efectiva de la pertenencia, que no se circunscribe sólo a los días de partido sino que se repite cotidianamente. Infinidad de cánticos expresan esta práctica:

"Yo soy de Gimnasia,

vago y atorrante,

me gustan los Rolling y los estimulantes,

porque tengo huevos,

voy a todos lados,

vamos a la cancha todos descontrolados ".

El uso de drogas y alcohol tiene que quedar bien claro:

"Dicen que estamos todos de la cabeza,

pero al basurero no le interesa,

tomamos vino puro en damajuana

y nos fumamos toda la marihuana".

Por otro lado, el dolor, resultado de los enfrentamientos, es oculto o disimulado. Los miembros de la hinchada exhiben su cuerpo como resistente a partir de la falta de manifestación del dolor. En una oportunidad el Negro José Luis, uno de los líderes más emblemáticos de la 22, cayó desde un paraavalanchas y golpeó su cabeza contra el suelo. La gravedad del golpe hizo pensar que podría haber muerto pero, por el contrario, el capo se paró, subió nuevamente al paraavalancha y, siguió arengando a sus compañeros y cantando, como si nada hubiese pasado. Mediante la resistencia del cuerpo se demuestra el aguante. Los miembros de la banda, al probar su resistencia y tolerancia al dolor manifiestan su aguante.

Quizás reflejar la historia de vida de uno de los jefes de la hinchada permita comprender los significados sociales que este grupo tiene respecto a un cuerpo aguantador, a un cuerpo fuerte y vigoroso.

El Loco Fierro, como se le conoce, fue y es un referente, un modelo de cuerpo que resume esas prácticas, representaciones y consumos que los integrantes de la banda, pasados y actuales, aspiran poseer. Un cuerpo fibroso, de músculos marcados, no grosso (para usar una expresión popular en referencia al tamaño $0^{5}$ ), sino más bien un cuerpo marcado, delineado, de gran agilidad

5 Los integrantes de "la hinchada" poseen usos, representaciones y consumos que se distinguen de otros grupos sociales respecto al cuerpo (Garriga, 2006). 
y fuerza, cuyos puños se han encargado de afirmar en varios enfrentamientos, muchos de ellos contra el enemigo numero uno: la policía.

Este antihéroe supo construir en el imaginario del resto de la hinchada un modelo de identificación, por su forma de ser y su carisma de líder. Dice T, uno de los actuales jefes de la banda: "El Loco Fierro era como un padre para mí, de corazón blando con los débiles y de corazón duro con los que se hacían los guapos". Otro entrevistado nos hablaba sobre las bondades del loco: "el Loco no era jefe, el jefe te manda a hacer y él, mira... el Loco era líder, un líder te dice vamos a hacer esto y lo hace junto con vos".

Sus subalternos o, en expresiones nativas, aquellos que caminaban con él, sentían y sienten, como lo demuestran con canciones, banderas y placas recordatorias una admiración extraordinaria. Sin duda, esa admiración es producto de dos tipos de atributos. Por un lado, los de carácter físico: destreza, agilidad y fuerza. Por otro lado, los más cercanos al mundo de los valores y los sentimientos, un hombre generoso, definido por un periodista radial, como un Robin Hood moderno.

En las entrevistas realizadas siempre se señaló que el Loco Fierro poseía aguante. Uno de los entrevistados repitió: "un aguante espectacular"; diciendo que siempre en los combates iba al frente. Los sujetos que van al frente del grupo son los más respetados por el resto de los hinchas. La condición de que unos pocos sujetos sean los que forman la primera fila de la hinchada, la línea de fuego, no implica la falta de aguante del resto de los hinchas que los siguen. De esta forma, los hinchas que van atrás de estos sujetos también son poseedores del aguante por el solo hecho de participar en el combate, pero poseen un estatus diferente al de los sujetos que ocupan las primeras posiciones. Estar al frente del grupo es de gran importancia, ya que es a través de los lugares de participación como los sujetos adquieren distinto estatus de aguante.

El mismo nombre de la hinchada, la 22, surge como reconocimiento al apodo del líder. Además, éste era un número cabalístico de Marcelo Amuchástegui -El Loco- que ensamblaba justo con su personalidad. Así lo expresan algunos de sus amigos: "El veintidós en la quiniela es el loco y Marcelo era un loco lindo; por eso, a la banda, la llamamos la veintidós, apodo que nace con Marcelo (Fierro) en vida y que aún hoy perdura como un especie de homenaje al eterno líder".

Esta presencia se materializa con el entierro de las cenizas de ese cuerpo aguantador en la cancha del club, ceremonia fúnebre que despertó gran inquietud en el mundo futbolístico y político. Sólo cabe recordar que parte de la comisión directiva y hasta un juez federal, cercano al club, junto con algunos integrantes de la barra del Loco Fierro exclamaron “ipresente!” en el entierro acontecido en el estadio. En la organización interna de la barra se abre un paréntesis después de la muerte de Marcelo. Dice H: "Con el loco estábamos más organizados. Durante los años ‘80, fue el grado de mayor esplendor que supimos tener. Fuimos los únicos que, por ejemplo, llevamos al bandera grande a la Boca y que preparamos un ataque con bombas molotov, y todo capitaneado por Marcelo." (Lugarteniente de Marcelo Amuchástegui, entrevista realizada en agosto de 2008)

Una nota periodística, desarrollada por periodistas dedicados al área deportiva de un matutino de la ciudad de La Plata, Provincia de Buenos Aires, testimonia el sentido simbólico y real que guardaba el Personaje Marcelo Amuchástegui, alias "El loco fierro". Para el resto de la hinchada, la ceremonia fúnebre que se brindó en su honor, en la que incluso participó un Juez, da cuenta de la magnitud de tal personaje. Para los hinchas (para absolutamente todos, sin distinción de prácticas, ni de clase social), el Loco Fierro era parte del club Gimnasia y Esgrima La Plata; era el símbolo del hincha emblemático, del aguante en persona, y lo sigue siendo.

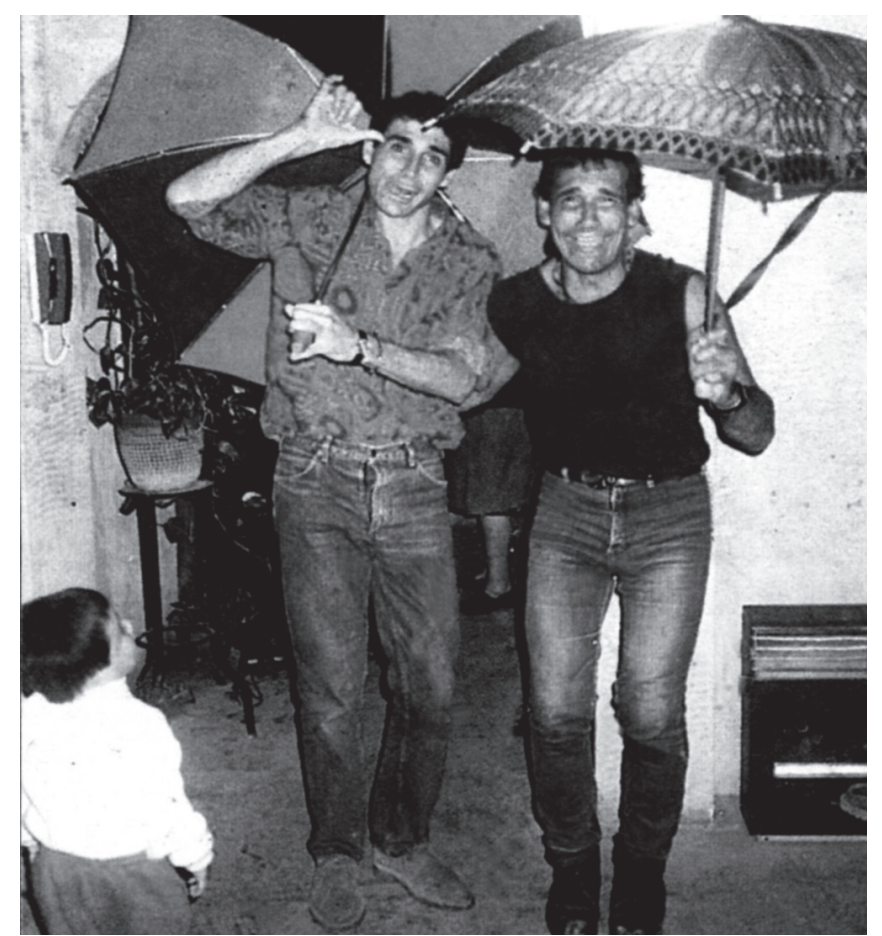

Marcelo "Loco Fierro" Amuchástegui, a su izquierda "El negro" José Luis Torres 
Marcelo, el "Loco Fierro"

El año pasado, un hincha trató de suicidarse detrás del arco de la cancha de Gimnasia en donde arrojaron sus cenizas. Su figura mítica es inmortalizada domingo a domingo por las banderas que lo recuerdan como si hubiese sido el 10 de un equipo campeón. Sin embargo el personaje fue el jefe de la barra brava gimnasista: el "Loco Fierro". Ese difunto líder se llamaba Marcelo Amuchástegui. Como Pablo Prado, murió bajo las balas policiales. Aquel jueves de comienzo de los años '90 un grupo de policías rosarinos le tendió una emboscada que desembocó en un confuso enfrentamiento. "Le dispararon por la espalda”, aseguran aún hoy los triperos más fanáticos. "Fierro era un loco. Me acuerdo que enfrentó a la hinchada de Platense con un palo de escoba", recuerdan aún hoy en las tribunas de la cancha del Bosque. También como Prado, Fierro estuvo involucrado en innumerables robos, tiros y enfrentamientos con barra bravas de otros clubes. En sus casi diez años de hegemonía al frente de la barra del equipo platense, Fierro estuvo detenido en varias oportunidades. Los hinchas creen que el enfrentamiento en el que finalmente es muerto por la Policía, tiene relación con una de sus detenciones. "La Policía rosarina se la había jurado, pero igual viajó para ver un partido contra Rosario Central. De ese viaje volvió muerto", recuerda un viejo simpatizante tripero. Su cuerpo fue cremado en el cementerio local y sus cenizas distribuidas detrás del arco del Paseo del Bosque, donde domingo a domingo los gimnasistas gritan por su equipo, bajo la "batuta" del "Loco Fierro". Dice la leyenda que en su velorio se formó una larga fila de fanáticos que lo despidieron con un beso en la frente. Ese día, la hinchada de Gimnasia estuvo acompañada por la barra brava de Estudiantes, que fuera de los estadios mantenía una relación de respeto con Fierro. Su muerte despertó las ambiciones de grupos antagónicos dentro de la barra gimnasista, al punto en que durante la copa Conmebol, en un partido que el equipo local jugaba contra O'Higgins, en 1991, hubo un enfrentamiento que terminó con varios heridos de bala. Aún hoy, 10 años después de su desaparición, no hay en la hinchada una figura que hiciera sombra sobre su figura. ${ }^{6}$

Ahora otros cuerpos ocupan el lugar del emblemático líder, cuerpos aguantadores, cuerpos de machos, cuerpos grosos o más grosos que el de Marcelo Amuchástegui,

6 Nota registrada en el diario HOY de la ciudad de La Plata, en el transcurso del año 1991. pero que todavía no han logrado marcar la impronta que el antiguo líder tuvo.

Entre los de la Guardia Vieja ${ }^{7}$, e incluso entre los menos radicalizados, como los espectadores comunes, se escuchan relatos que sentencian que ya no es lo mismo, que la hinchada perdió presencia. El Loco Fierro, el cuerpo aguantador, macho y bravo, aún se presenta en cada partido en donde juega el equipo; su simbología es parte de la señal identitaria que conforma el colectivo.

\section{"Los del palo"}

"Acá está la gloriosa hinchada del Basurero, la que fue a todas partes cuando fuiste al descenso, a pesar de los años, los momentos vividos, siempre estaré a tu lado,

Basurero querido".

"Los momentos vividos" a los que hace referencia la canción son las experiencias sociales que delimitan fronteras entre nosotros y otros. Estas fronteras se sustentan en prácticas particulares y distintivas; prácticas corporales. El enfrentamiento físico y la participación en combates son las señales que delimitan esta identidad. Sin duda, estas prácticas del ser de la banda van denotando una particular forma de ser.

Tal vez, la pertenencia obedece a la necesidad de encontrarse protegido, contenido. Tal vez represente una estrategia de refugio, de marginalidad compartida. La frase de un hincha señala los sentidos de pertenencia al mismo tiempo que define las prácticas distintivas: "nosotros antes del partido paramos en el boliche del gordo, tomamos unas cervecitas, nos colocamos, y arrancamos para la cancha". En estas palabras puede interpretarse claramente que lo espacial contribuye a la identificación de un nosotros. La particular forma de entrar al estadio, con movimientos ensayados, con despliegue de estandartes, siempre procurando que los otros estén atentos a ese ejército que llega a tomar posición estratégica y siempre respeta iguales espacios geográficos en la tribuna. La barra tiene sus espacios, en el barrio, en el club y en la tribuna; espacios que les pertenecen y los definen.

7 La guardia vieja es una categoría utilizada para determinar otro subgrupo componente del colectivo hinchada. Ellos tienen prácticas particulares que los distinguen de los otros subgrupos como son: a. Los espectadores comunes; b. Los fanáticos; c. Los duros pero nómades; d. La banda o el "núcleo" duro 
Nadie, ni siquiera aquellos que entran por primera vez a un estadio, pueden desentenderse de que entre el público hay un grupo distinto a la generalidad y que ese grupo se encarga permanentemente de demostrar sus diferencias. Por ejemplo, cantan:

"Todos nos llaman los negros de mierda

la policía nos persigue sin cesar

pero la gente que sabe y comprende

que a Gimnasia lo queremos de verdad “

Se enuncian tres marcas identitarias: la negritud, la constante persecución policial y, por último, el amor incondicional a la divisa. Éstas son marcas apropiadas por la banda como señal de pertenencia. No todos los hinchas cantan esta canción; la platea no la canta, los espectadores comunes tampoco. Éste es un ejemplo de demarcación territorial simbólica dentro del mismo club. Diferencias hacia adentro: somos todos del Lobo pero no somos todos iguales. Es notable el acento puesto en la incondicionalidad, en el aguante a la adversidad como señal que los distingue de otros espectadores que no son tan leales.

Estas canciones denotan distinción, muestran una otredad. Marcan y fundamentan, a través de la poética popular, que se pertenece a algo. Sin duda que los espacios propios, las jergas -códigos de lenguaje-, formas particulares de vestirse, definen la inclusión de un grupo de pares. Pero son las acciones corporales las que comunican, las que expresan algo más profundo que la simple práctica que se visualiza. Principalmente, las acciones violentas dejan marcas que expresan que se es así, que se pertenece a un grupo con identidad propia. Un informante nos decía: "nosotros no combatimos con la gilada, con la gente que va con la familia o los chicos, nosotros vamos al frente contra la otra hinchada, no somos como los putos de Platense que se la agarran con los giles". La participación en combates contra iguales define a "los del palo", define a los que compiten por el aguante; competencia corporal.

\section{A modo de conclusión}

A lo largo del presente trabajo he intentado señalar y presentar diferentes prácticas que desarrolla el colectivo social "hinchada", focalizándome específicamente en el sector de la misma que defino como los duros y los del palo, dos sub grupos que conforman la "banda". Dichas prácticas fueron seleccionadas utilizando un eje temático: la identidad. Para ser más preciso, la selección, análisis y posterior interpretación y comprensión de dichas prácticas (producto de un arduo trabajo de campo etnográfico) se llevó a cabo teniendo como horizonte teórico las acciones que estos sujetos realizan en escenarios y tiempo determinados y analizando cómo a través de dichas acciones van construyendo su identidad. Ésta es concebida justamente como construcción social, lo que niega la concepción esencialista, que concibe a la formación de la identidad como un elemento estanco, estático. Desde dicho esencialismo, se desconoce la historia propia del grupo, que va construyendo constantemente su propia identidad.

En estas prácticas constituyentes de identidad, el cuerpo es el actor principal. Un cuerpo que se afana por aparecer en escena de manera material y simbólica. Prácticas materiales como el "combate" y prácticas simbólicas, como la palabra, dan cuenta de la construcción identitaria. En relación directa con las prácticas materiales, puede observarse la manera en que el cuerpo es utilizado como manifestación, entendida no sólo como movimientos y reflejos orgánicos, sino como algo más complejo, como son las emociones, los pensamientos y los sentimientos. A estas prácticas de carácter material debemos sumarles las simbólicas, que según Bourdieu son necesarias para que los individuos legitimen y justifiquen su existencia. La ausencia de dichas justificaciones llevaría a los sujetos a la pérdida de su identidad social. Algunas de estas prácticas son, por ejemplo, los rituales que desarrollan los pertenecientes a la "banda de Fierro": ¿Cómo y cuándo viajar a otras canchas? ¿Qué hacer antes de entrar a la cancha? ¿Cómo mostrar y demostrarse ante la mirada examinadora de los otros?

Esto constituye un lenguaje corporal y, por lo tanto, una forma de ser, una existencia y expresión que se presenta a través de su corporeidad. Esta corporeidad, esta forma de ser, de existir y de expresarse es lo que va a ir construyendo la identidad del grupo.

\section{Referencias}

Boltanski, L. (1975): Los usos sociales del cuerpo, Buenos Aires: Ediciones Periferia.

Bourdieu, P. (1994): Deporte y clase social. AA.VV: Materiales de sociología del deporte. Madrid: Ediciones de la Piqueta.

Crisorio, R. (1998): Constructivismo, cuerpo y lenguaje. Revista Educación Física y Ciencia No. 2. Buenos Aires.

Garriga Zucal, J. (2006): Acá es así. Hinchadas de fútbol, violencia y territorios. Avá, Revista de Antro?pología, número 9. Universidad Nacional de Misiones, Posadas, Argentina. 
ANEXOS FOTOGRÁFICOS

Fotografía testimonial

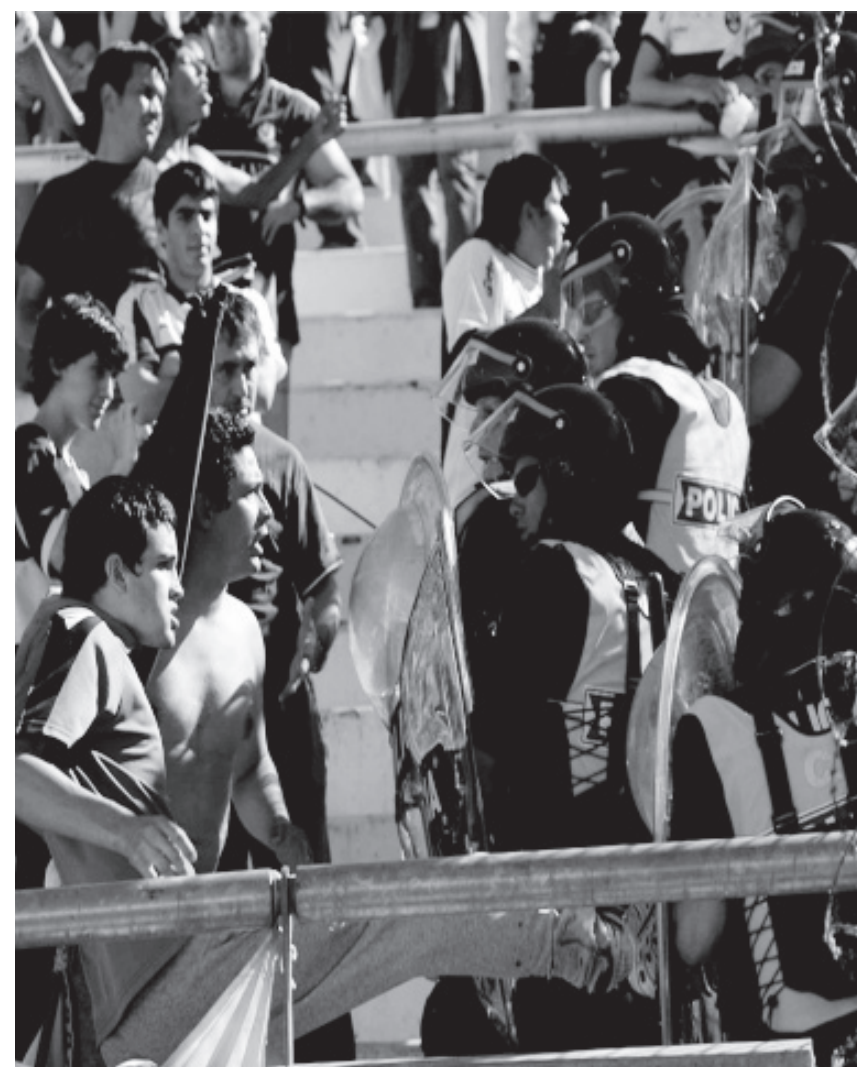

Hinchada: Núcleo duro enfrentándose con la policía
Fotografía testimonial

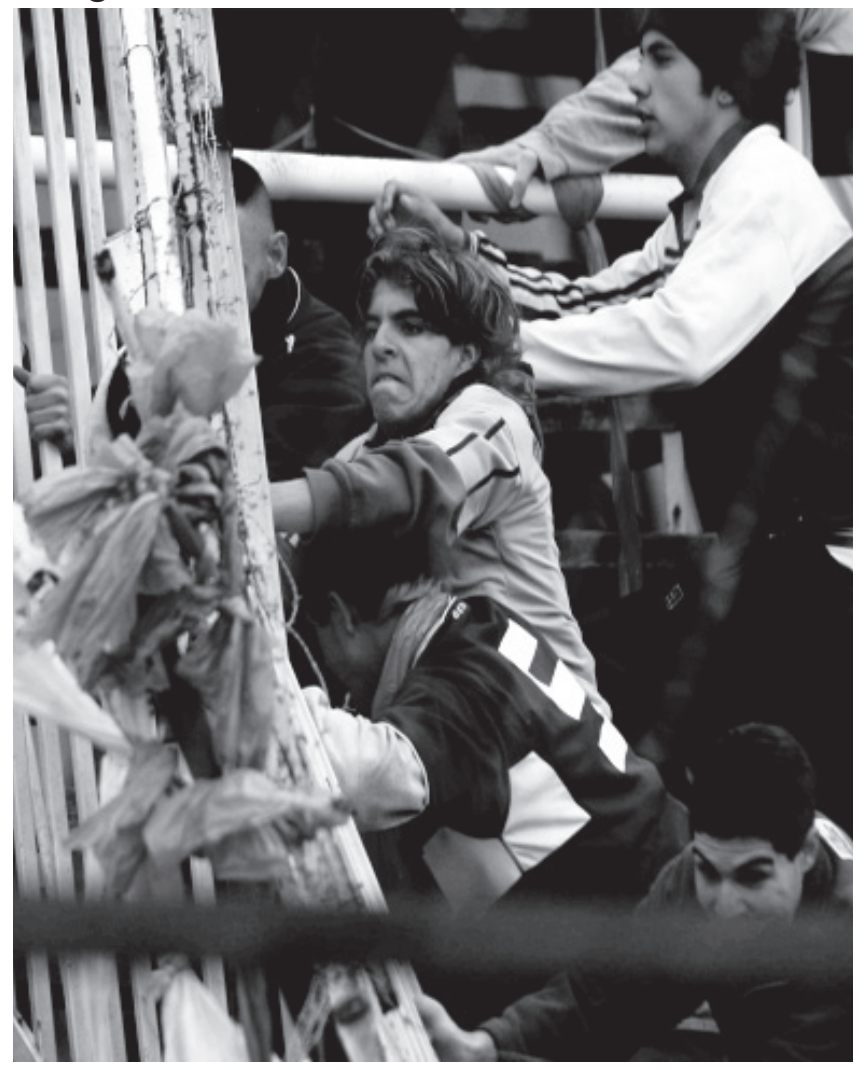

Hinchada: Núcleo duro intentando saltar la valla para toparse con la hinchada oponente

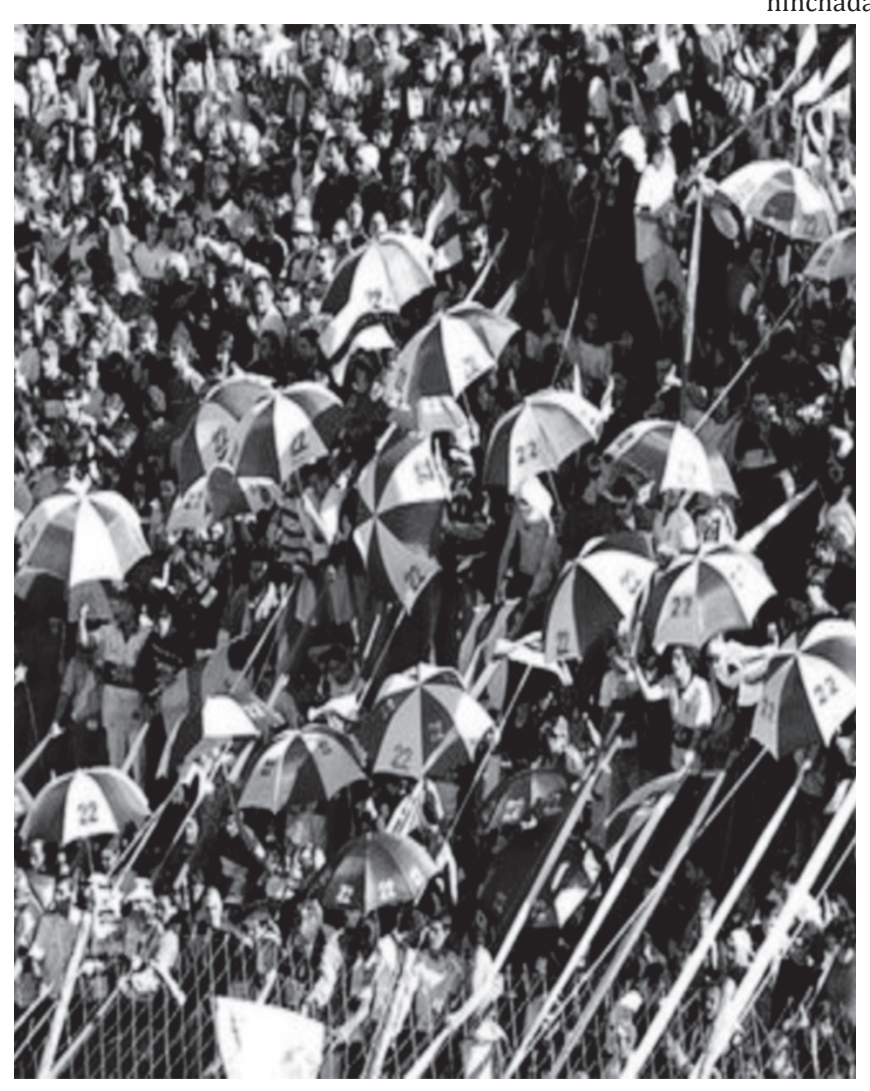

La imagen nos muestra con suma elocuencia la hinchada del Club

Gimnasia y Esgrima La Plata, conocida con el nombre: LA "22" 